Slavica

bruxellensia

\section{Slavica bruxellensia}

Revue polyphonique de littérature, culture et histoire

slaves

$6 \mid 2010$

Linguistique russe

\title{
Inga Iwasiów, Ku słońcu
}

\section{Halina Scholtysik}

\section{(2) OpenEdition \\ Journals}

\section{Édition électronique}

URL : http://journals.openedition.org/slavica/356

DOI : 10.4000/slavica.356

ISSN : 2034-6395

\section{Éditeur}

Université libre de Bruxelles - ULB

\section{Édition imprimée}

Pagination : 71-72

ISSN : 2031-7654

\section{Référence électronique}

Halina Scholtysik, «Inga Iwasiów, Ku słońcu », Slavica bruxellensia [En ligne], 6 | 2010, mis en ligne le 15 juin 2010, consulté le 22 septembre 2020. URL : http://journals.openedition.org/slavica/356 ; DOI : https://doi.org/10.4000/slavica.356

Ce document a été généré automatiquement le 22 septembre 2020.

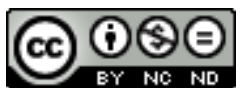

Les contenus de Slavica bruxellensia sont mis à disposition selon les termes de la Licence Creative Commons Attribution - Pas d'Utilisation Commerciale - Pas de Modification 3.0 France. 


\section{Inga Iwasiów, Ku słońcu}

Halina Scholtysik

\section{RÉFÉRENCE}

Inga Iwasiów, Ku słońcu, Varsovie, Świat KsiĄżki, 2010, 318 p. 
$1 \quad K u$ słońcu (Vers le soleil), le dernier livre du professeur de l'Université de Szczecin Inga Iwasiów, est la continuation de son roman Bambino, qui avait été très bien reçu par la critique et même nominé à d'importants prix littéraires. Même si cela permet d'entrer plus facilement dans les destins entremêlés de trois générations de héros, il n'est toutefois pas nécessaire de connaître la première partie pour lire ce nouveau tome.

Inga Iwasiów se concentre ici sur quelques personnages unis par des liens vagues et compliqués, ce qui nous permet de suivre une galerie de comportements variés. Outre cela, elle aborde néanmoins des problématiques extrêmement vastes: l'histoire, l'amour atypique et difficile, la responsabilité, la perte, la féminité, la vieillesse, le temps qui passe et la mort.

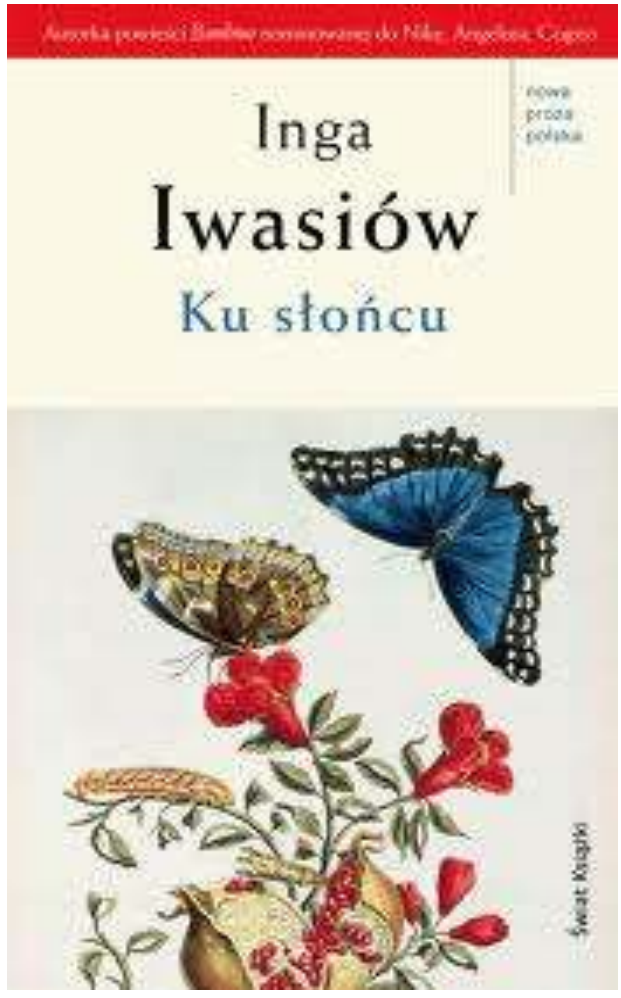
Les destins des personnages sont décrits sur fond des changements sociaux et politiques qui ont surgi ces trente dernières années. Cependant, l'auteur ne semble pas chercher à produire une synthèse de la réalité polonaise.

3 L'action ne se passe qu'en apparence dans le Szczecin d'aujourd'hui. En effet, peu de choses se déroulent à l'époque actuelle: Magda, la fille devenue adulte des héros de Bambino, revient de l'étranger pour veiller sa tante Ula, qui est mourante. À cette occasion, elle est amenée à affronter son passé. Magda est partie en Occident à un moment où ce n'était pas possible pour tout le monde. Elle a habité à Berlin, à Londres et enfin dans une petite localité dans les environs d'Amsterdam. Elle est donc une représentante d'une nouvelle génération, une citoyenne du monde qui connaît les langues et a fait carrière, une femme moderne. Et pourtant, elle n'est pas tout à fait convaincue (tout comme les autres héros d'Iwasiów, que ce soit Tomek ou sa femme Sylwia) que ce soit le meilleur scénario qu'elle eût pu réaliser. Dans le fond, bien qu'elle puisse se sentir «chez elle» un peu partout, elle n'appartient à aucun endroit. Et comme cela s'avérera, rien ne la lie déjà plus avec Szczecin.

Dans le roman, le rôle de l'Occident est primordial. C'est un lieu où, bien sûr, l'on vit mieux, mais aussi où l'on regarde la vie autrement. Les atouts importés de l'Est (la langue) n'ont finalement aucune valeur. Il faut vite revoir ses idées du début (comme par exemple les études de slavistique de Magda) en fonction de la réalité et choisir l'informatique, qui a de l'avenir, même si cela ne nous intéressait pas dans le "vieux " monde. Après un certain temps, nous payons néanmoins pour ces choix: nous connaissons parfaitement les langues étrangères et pourtant "l'automatisme de la langue [maternelle] commence à gémir » (p. 10).

5 L'atmosphère du roman s'épaissit à travers les rétrospections. En vérité, c'est dans celles-ci que «se passe » le plus important pour les héros. Le lecteur est emporté dans d'autres réalités, le plus souvent potentielles. Les héros doivent effectivement faire face 
au passé, à des affaires pas réglées, pas terminées, dont ils n'ont sans doute pas compris la signification en son temps. Et c'est de ce point de vue qu'ils regardent leur propre vie, vie qui semble bien organisée, mais qui aurait pourtant pu se dérouler autrement.

Les héros de Ku stońcu ce sont déjà des gens d'une nouvelle époque. Bien qu'ils vivent dans une Pologne libre, il apparaît que cette liberté ne leur facilite pas du tout la vie, le développement et parfois elle cause même de nouveaux problèmes (comme dans le cas du père de Marek qui doit subir un procès de lustration). En ayant une liberté de choix aussi grande, l'homme a certaines limites: elles sont en lui, dans ses peurs et ses émotions réfrénées. La vie d'aujourd'hui des héros a été influencée par des décisions du passé, pas toujours conscientes, qu'il fallait prendre essentiellement au vu de la situation politique (la loi martiale). Dans cette perspective, Ku słońcu commence donc là où se terminent les destins des héros de Bambino : au début des années 1980 et couvrant une période de trente ans.

Dans le roman d'Iwasiów, des faits, des événements d'apparence superflus occupent finalement une place importante dans la vie des héros, les liant entre eux. Trouvée par hasard dans une lettre pornographique, Luiza va constituer un élément inhérent de l'amitié de Tomek et de Magda. Le fait que Małgorzata ait reproché dans le passé son travail de recherches sur Hildegarde, une mystérieuse mystique et émancipatrice du XVIII ${ }^{\mathrm{e}}$ siècle, va devenir pour Marek un prétexte pour vivre une romance avec son professeur, bien plus âgée que lui.

On peut reprocher à ce livre d'être difficile et exigeant, et ce en raison de la multiplicité des trames et des personnages ainsi que de la narration, qui comprend les rêves et les visions des protagonistes. Cependant, comment traduire autrement les peurs et les rêves réprimés? Comment laisser imaginer cette partie intérieure la plus souvent étouffée de notre vie et de nous-mêmes, le monde renfermé de nos émotions emmêlées, équivoques et parfois à peine conscientes? Des blessures pas guéries, des non-dits, une incertitude ou des décisions prises autrefois leur correspondaient, les autres scénarios - toujours potentiels, car personne ne nous donnera jamais la garantie qu'ils pouvaient se réaliser - qui défilent dans notre tête à nous en déprimer. Des étonnements et des désenchantements, comme si la découverte que Hildegarde n'existait pas en réalité, n'était qu'une mystification. C'est cela justement qui remplit la vie la plus intime des héros d'Iwasiów, et leurs émotions ne laissent pas le lecteur indifférent car ce sont les siennes.

\section{INDEX}

Index géographique : Pologne, Szczeciń

Index chronologique : XXe siècle, XXIe siècle

Mots-clés : littérature polonaise 
AUTEURS

HALINA SCHOLTYSIK

Assistante Université libre de Bruxelles 